This item was submitted to Loughborough's Research Repository by the author.

Items in Figshare are protected by copyright, with all rights reserved, unless otherwise indicated.

\title{
Population inequality: the case of repeat crime victimization
}

PLEASE CITE THE PUBLISHED VERSION

PUBLISHER

(C) AB Academic Publishers

LICENCE

CC BY-NC-ND 4.0

\section{REPOSITORY RECORD}

Tseloni, Andromachi, and Ken Pease. 2019. "Population Inequality: The Case of Repeat Crime Victimization". figshare. https://hdl.handle.net/2134/848. 


\title{
POPULATION INEQUALITY: THE CASE OF REPEAT CRIME VICTIMIZATION
}

\author{
ANDROMACHI TSELONI* \\ University of Macedonia, Greece
}

\author{
KEN PEASE** \\ University College, London, UK.
}

\begin{abstract}
This paper employs data from the 2000 British Crime Survey for England and Wales to discuss ways of illustrating the degree of inequality in the distribution of crime victimization. In particular, Lorenz curves are presented for major crime categories, i.e. property, personal and vehicle crime, and their components are presented. They are fitted both nationally (i.e. to victimized and non-victimized people) and amongst victims. Crime Lorenz curves over victims illustrate repeat victimization. Additional repeat victimization statistics, such as concentration, the percentage of repeat crimes and the percentage of repeat victims, are also shown. Threats and assaults are the most recurring crimes, whereas theft of vehicles shows low rates of repetition within a year.
\end{abstract}

\section{INTRODUCTION}

A central theme of the economic literature from its beginnings has been the distribution of a nation's wealth among its citizens (Marshall, 1890). This is now commonly assessed by the shape of the so-called Lorenz curve (Marsh, 1988). Criminology, a relatively new science, has traditionally dealt with typologies of crimes and offenders (Garland, 1997). Only in the late 1970s did criminologists become focally concerned with victims and strategies which aim to protect the victim rather than deter or punish the offender (Karmen, 2001). The Kirkholt burglary prevention project (Forrester et al., 1990) showed that total crime rates may decline in an area as a result of crime prevention which focuses on those hitherto victimized. Arguably, preventing crimes against prior victims is cost-effective (Farrell, 1995) and free of moral or other inferences about the victim (Pease, 1998). An overview of repeat victimization research and its practical implications are given in Pease (1998).

* Associate Professor, Department of International \& European Economic \& Political Studies, University of Macedonia, Egnatia 156, P.O. Box 1591, 54006 Thessaloniki, Greece. Tel./Fax GR-2310-891402. To whom correspondence should be addressed.

** Professor, Jill Dando Institute, University College London WCIE 6BT, UK. 
This short paper aims to depict victimization in terms of the cumulative distributions of crime, thereby inviting consideration of the distribution of crime alongside other social goods or ills. The traditional economic notion of inequality is applied to the distribution of crimes across (i) the general population and (ii) victims. To this end Lorenz curves ${ }^{1}$ are fitted at the national level and across victims. Indicators of crime concentration and repeat victimization are also presented. The paper ends with a discussion of possible caveats from fitting inequality statistics to crime data.

The empirical distribution of crimes employed in this analysis is drawn from the British Crime Survey (henceforth BCS) 2000 for England and Wales, which was a large-scale multi-stage stratified survey of 17,189 individuals, one individual per household, run by the Home Office Research, Development and Statistics Directorate (Kershaw et al., 2000). To be precise, 'national' refers here to two nations, namely England and Wales.

At this point distinguishing between the various ways that repeat victimization manifests itself might be useful. Multiple victimization refers to more than one crime incident by different crime types which have occurred during a period of time, conventionally a calendar year. For instance, an individual receives a violent blow during a fight, is threatened by a work colleague and his house gets burgled with damage within a year. Albert Reiss (1980) presented a 'crimeswitch matrix' (Reiss, 1980, p. 41) of multiple crimes based on the 1972-1975 U.S. National Crime Survey. He found that recurrence of crimes to the same households and their members was more frequent than chance alone would have allowed. Identifying multiple victims may fail if crime prevention efforts target a specific crime type. There is evidence, however, of cross-crime benefits even when prevention is focused on a single crime type (Pease, 1998; Farrell, 1995).

Repeat victimization means that victims experience the same crime type twice or more in a given period of time. The bulk of the related literature deals with repeats so defined (Farrell and Pease, 2001). The broader the crime category, for instance, property crime, the more likely repeats are essentially multiples. Even among crimes with the same legal label, there will be a diversity of criminal methods employed and harm suffered, such that legal repeats are experiential multiples. The two terms are used interchangeably in the related literature.

A special category of repeat crimes are referred to as series. Perhaps the best definition and, consequently, construction of series events to date, is the one given by the Home Office in the BCS questionnaire: 'were any of these [crimes] very similar incidents, where the same thing is done under the same circumstances and probably by the same people?' (Hales et al., 2000: p. 21). Series may make up a large portion of repeats, especially for crimes against the person (Chenery et al., 1996). While the definition of series used in BCS is admired, the reason for its use is economic, namely that only one interview is necessary for a series, whereas one interview is necessary for each non-series victimization. The number of incidents reported in a series is truncated at five, if six or more have been reported, for calculating national crime rates, presumably so that exagger- 
ation of one's chronic victimization does not drive total crime rates. This important issue will be revisited in the last section of the present paper.

\section{METHODOLOGY}

In this paper the distribution of crime is presented in the form of Lorenz curves drawn from the data of the 2000 BCS. Any standard statistics textbook (see for instance Marsh, 1988) describes how the Lorenz curve of income distribution is the result of plotting the cumulative (percentage) frequency of income against the cumulative (percentage) frequency of population (Marsh, 1988, p. 89). If the Lorenz curve coincides with the main diagonal of the square box shaped by the horizontal ( $\mathrm{x}$ ) and vertical (y) axis (the $\mathrm{x}$-axis represents percent population and $y$-axis percent of total income) and their parallels at 100 percent, income is equally distributed. In such a case, for instance, the poorest $25 \%$ of the population owns $25 \%$ of total national income (as do the $25 \%$ richest, making the terms richest and poorest meaningless in this limiting case). The more the Lorenz curve is pulled towards the low right corner of the box (the corner with $100 \%$ population and $0 \%$ income coordinates) the more unequal the distribution of income. In the extreme case that the Lorenz curve coincides with the 90 degrees corner, which is shaped by the horizontal and the right-hand vertical axis of the box, all national wealth belongs to just one individual, the richest 100 -th percent individual in the cumulative population distribution. The poorer $99.99 \%$ of the population has in this case no income at all. Self-evidently the first and last situations are purely theoretical. National Lorenz curves lie somewhere in between the main diagonal and the low right hand corner of the Figure box.

This analysis applies Lorenz curve analysis to crime rather than income. A large number of crime categories have been grouped into three standard criminal victimization aggregates, namely household, personal and vehicle crime victimization. The crime categories for this analysis are: (a) total household crimes (including vehicle crimes), burglaries and thefts from a dwelling, (b) total personal crimes, thefts/robberies, assaults and threats, as well as (c) total vehicle crimes and thefts from or of vehicles ${ }^{2}$. The period of study covers the calendar year 1999. As mentioned, series are truncated at 5 incidents according to BCS convention. This is dispensed with in the final section of the paper.

Lorenz curves for each of the above crime types have been fitted across the general population for personal crimes (category $b$ above), the number of households for property crimes (category a) and the number of households owning cars for vehicle related crimes (category c), showing how crime differentially burdens citizens. They are also fitted across victims of each crime type examined here. This allows us to investigate how crimes differentially burden victims. This has special relevance to the allocation of police resources. 


\section{DISTRIBUTION OF CRIMES AMONGST CITIZENS}

This section discusses how crimes are distributed nationally via populationbased Lorenz curves for aggregate crime categories and their components. Figures 1, 3 and 4 present cumulative population distributions for total household, total personal and total vehicle crimes, respectively. For instance, $80 \%$ of English or Welsh households did not experience any property crime at all during 1999 (see Figure 1). Thus the Lorenz curve coincides with the horizontal axis at 0 crimes for the lower $80 \%$ of households but it increases exponentially for the $20 \%$ of households which have been victimized. $97 \%$ of individuals 16 years old or older and $87 \%$ of vehicle owning households did not experience any personal or vehicle crime, respectively, during 1999 (see Figures 3 and 4, respectively).

The national Lorenz curve for burglaries, which is presented in Figure 2, is very steep due to the low prevalence of the offence. Lorenz curves for all other individual crime categories, namely thefts from dwelling, assaults, thefts and robberies, threats, thefts from vehicles and thefts of vehicles, are not presented in the paper. They showed nearly perfect 'inequality', i.e. essentially coinciding with the low right hand corner of the box. This implies that they burden a tiny proportion of the population, information which can also in part be gleaned from prevalence rates.

\section{DISTRIBUTION OF CRIMES OVER VICTIMS: REPEAT VICTIMIZATION}

Repeat victimization can be delineated via crime Lorenz curves over victims who, as discussed above, may constitute a very small proportion of the population. If the curve coincides with the main diagonal of the square box then each victim has experienced the same number of crimes, i.e. no repeat crimes have occurred. If it becomes steeper than 45 degrees then the more heavily victimized experience disproportionately more crimes. This form of analysis has particular relevance to police work, since the policing task essentially consists of choices about the distribution of effort across calls for service. These Lorenz curves properly provide a starting point for consideration of distributive justice in policing.

Figures 5 to 14 present Lorenz curves over victims for aggregate crime categories and their constituent individual crime types. Some $34 \%$ of householdvictims of property crime were repeatedly victimized. The most victimized $10 \%$ of households experienced roughly $30 \%$ of total household crimes in 1999 (see Figure 5). Equally, $28 \%$ of victims of personal crime suffered repeat incidents. The $10 \%$ of those most heavily burdened by crime encountered over $30 \%$ of total personal crimes (see Figure 8). Similar figures relate to total vehicle crime in Figure 12. As mentioned in the preamble to this paper, repeats within broad crime categories, such as those discussed above, are most likely to measure multiple victimization. Neither should one assume that repeat victims undergo 
TABLE 1

The extent of repeat victimization based on the 2000 British Crime Survey for England and Wales.

\begin{tabular}{lccc}
\hline Crime Type & Concentration & $\begin{array}{c}\% \\
\text { Repeat Crimes }\end{array}$ & $\begin{array}{c}\% \\
\text { Repeat Victims }\end{array}$ \\
\hline Total Household Crime & 1.71 & 61.5 & 34.3 \\
Burglary & 1.32 & 37.9 & 17.9 \\
Theft from a Dwelling & 1.46 & 50.0 & 26.9 \\
Total Personal Crime & 1.55 & 53.4 & 27.8 \\
Assault & 1.68 & 61.2 & 34.7 \\
Theft \& Robbery & 1.29 & 31.2 & 11.0 \\
Threat & 1.75 & 63.7 & 36.4 \\
Total Vehicle Crime & 1.51 & 53.7 & 30.1 \\
Theft from Vehicle & 1.35 & 42.7 & 22.5 \\
Theft of Vehicle & 1.13 & 19.1 & 9.7 \\
\hline
\end{tabular}

the same experience, notwithstanding the identical legal category of the events which they suffer. For many practical purposes, the aggregate curves are more useful than the offence-specific curves, since once police presence has been invoked, preventive intervention need not be limited to the crime type which precipitated that presence.

Threats and assaults are the most recurring individual crimes $(36 \%$ and $35 \%$ repeat victims; see Figures 11 and 9, respectively) since the $10 \%$ worst victimized individuals experienced roughly one quarter of all such crime. By contrast about $10 \%$ of victims of thefts and robberies or thefts of vehicle suffered the crime repeatedly within a year (see Figures 10 and 14, respectively).

Table 1 presents concentration rates, the percentage of repeat crimes and the percentage of repeat victims for each crime type examined. Concentration, namely the number of incidents over the number of victims (defined appropriately for each crime type) gives in a single figure the extent of repeat victimization (Tseloni et al., 2002). An alternative measure, which is widely used by Professor Graham Farrell (see for instance Farrell, 1992), is the percentage of crimes which are repeats. Both figures are by-products of building crime Lorenz curves and are presented in this study. The percentage of victims who have suffered more than one crime of the same type is a third measure of repeat victimization presented here. It is again easily deduced from crime Lorenz curves for victims. The three statistics are equivalent in measuring repeat victimization. Thus a variety of ways to quantify repeat victimization in a parsimonious manner exists and, given data reliability, such statistics can (and in the view of the authors should) be made readily available along with other national crime statistics. 


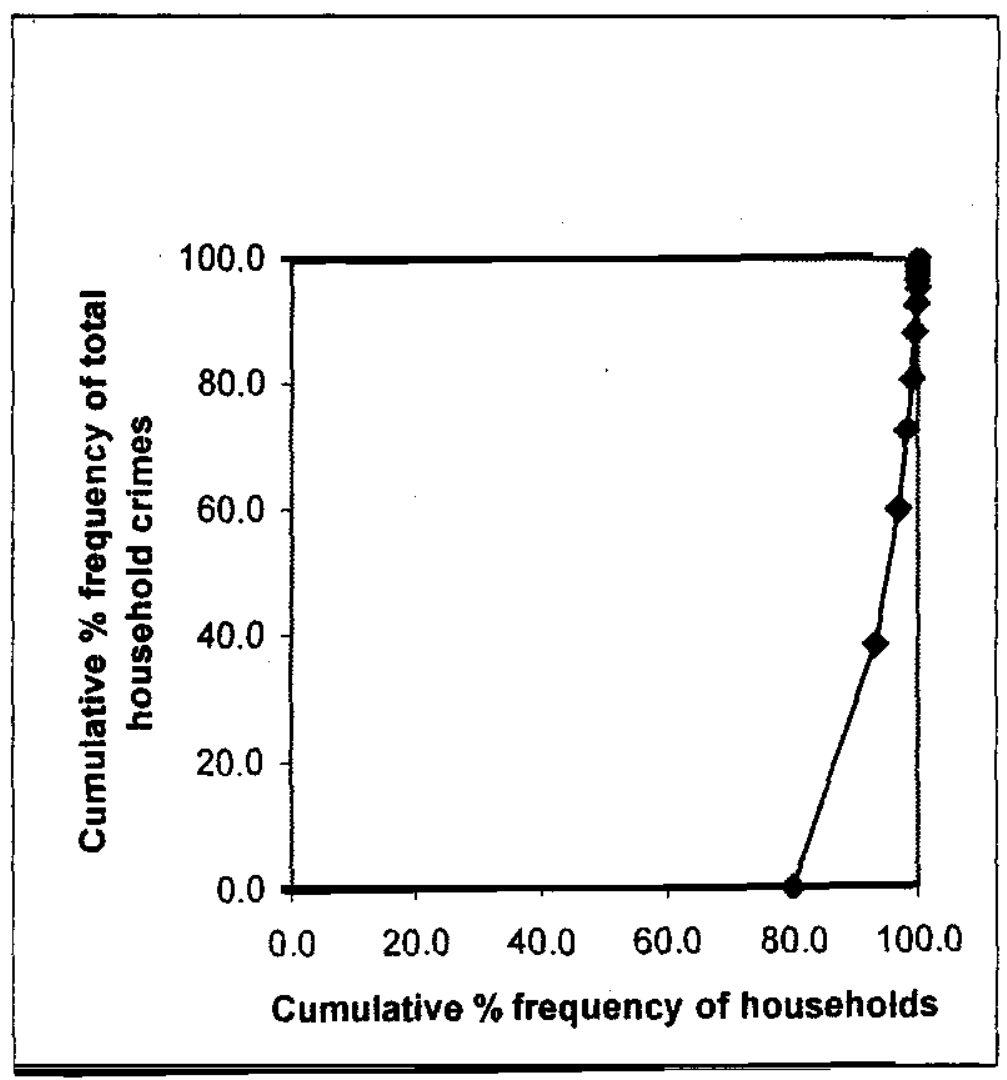

Figure 1. Lorenz curve for total household crimes.

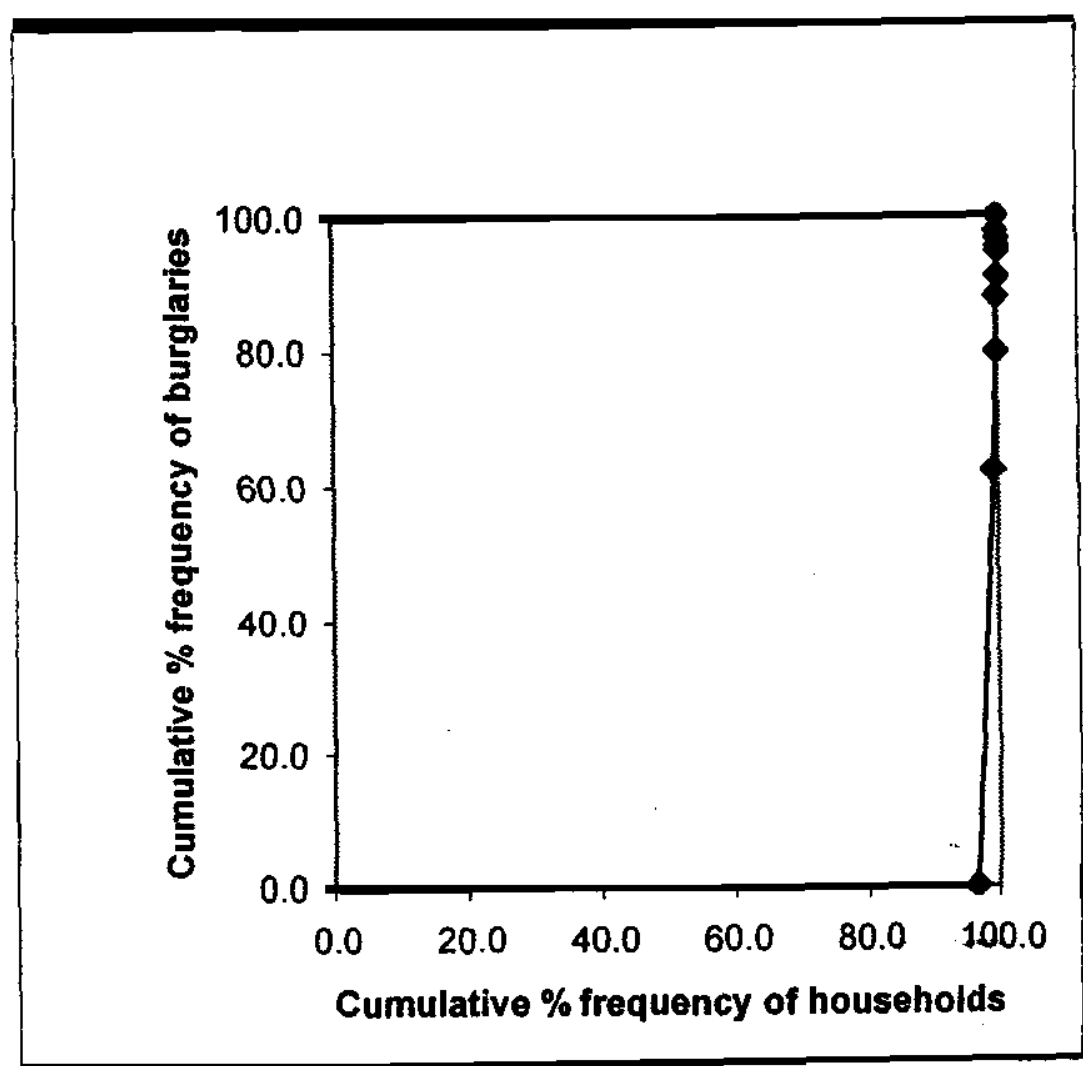

Figure 2. Lorenz curve for burglaries. 


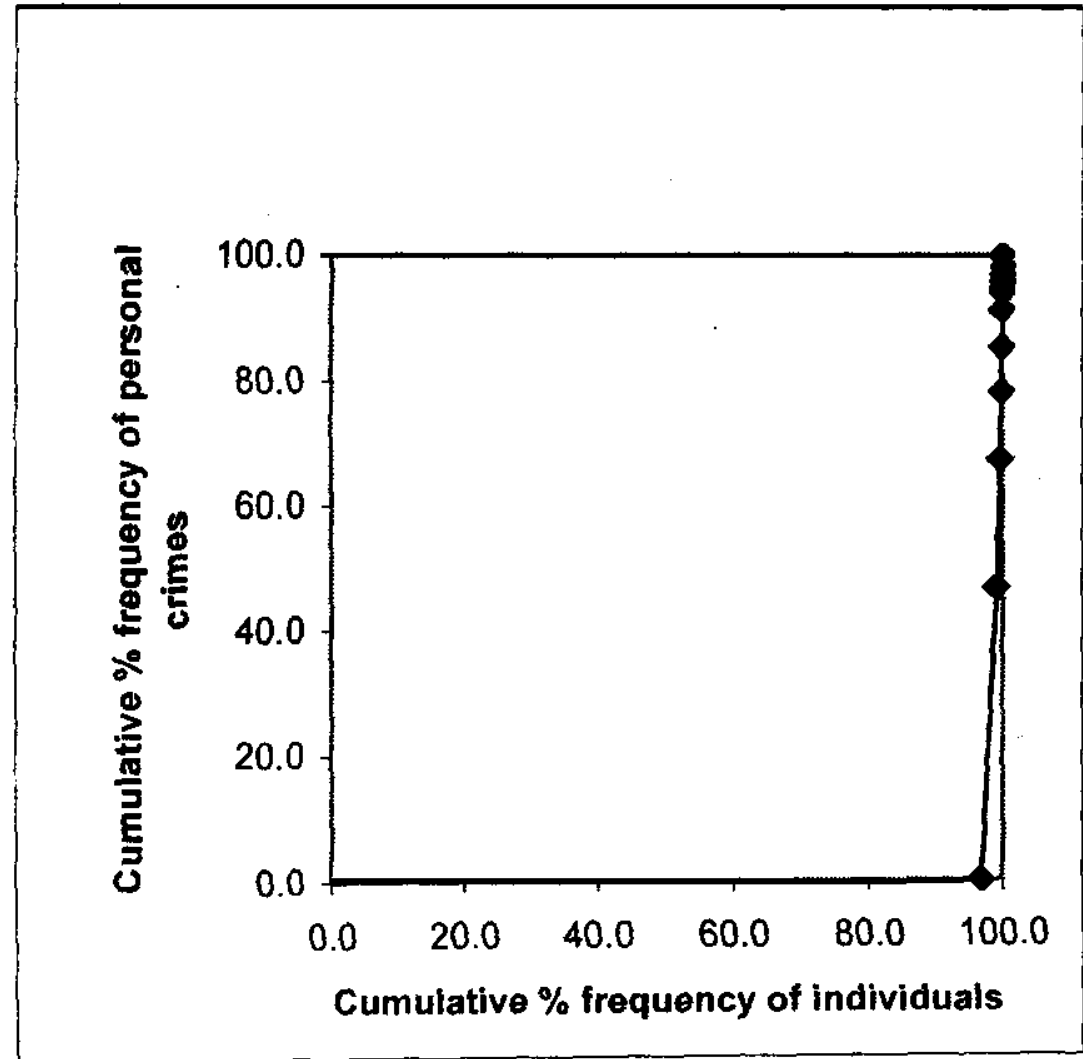

Figure 3. Lorenz curve for total personal crimes.

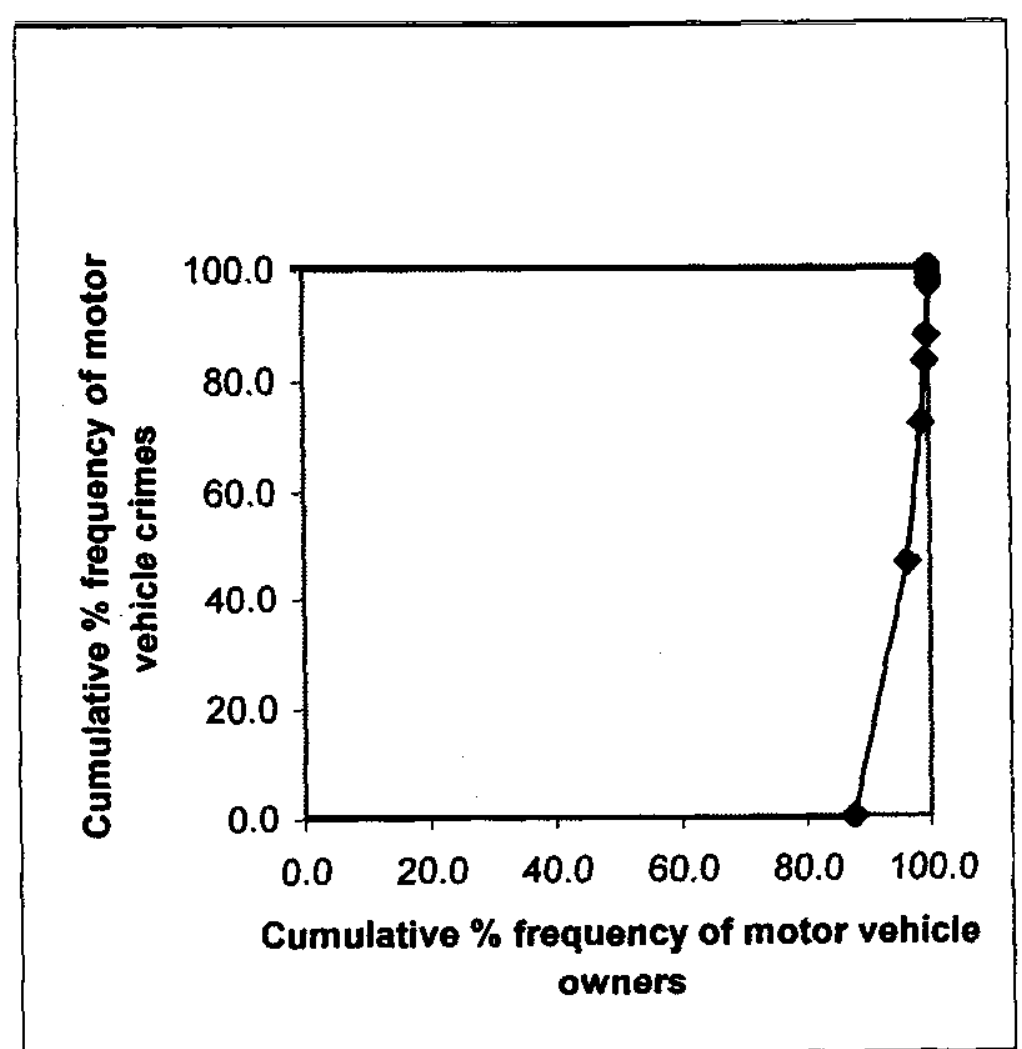

Figure 4. Lorenz curve for total motor vehicle crimes. 


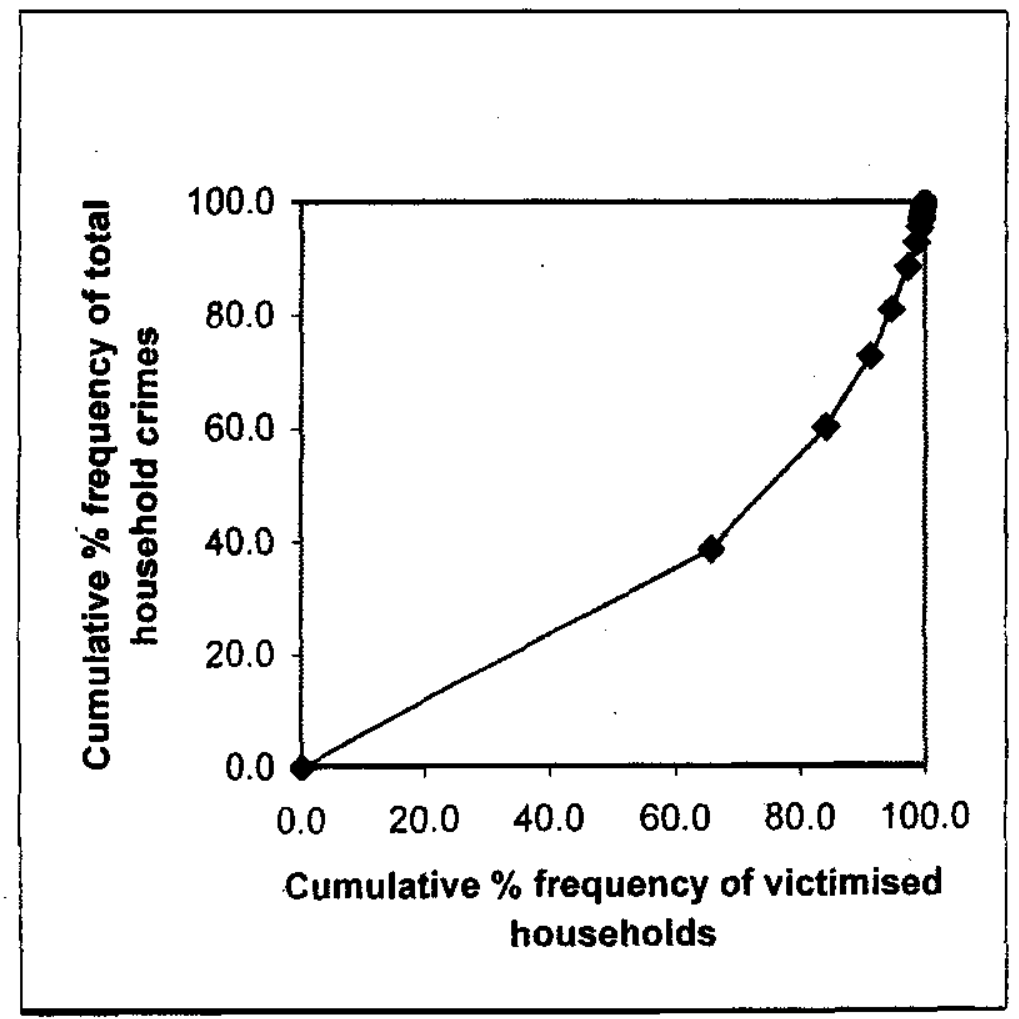

Figure 5. Lorenz curve for total household crimes over victims.

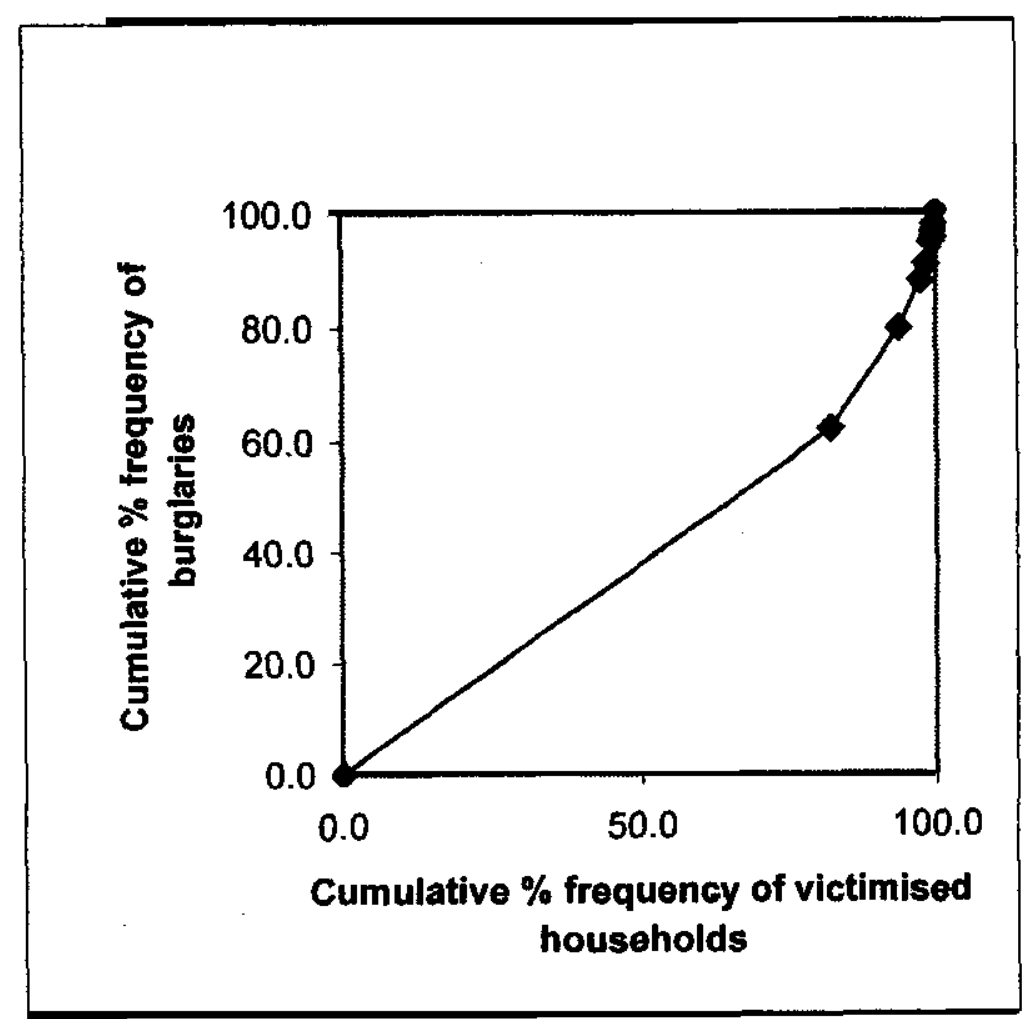

Figure 6. Lorenz curve for burglaries over victims. 


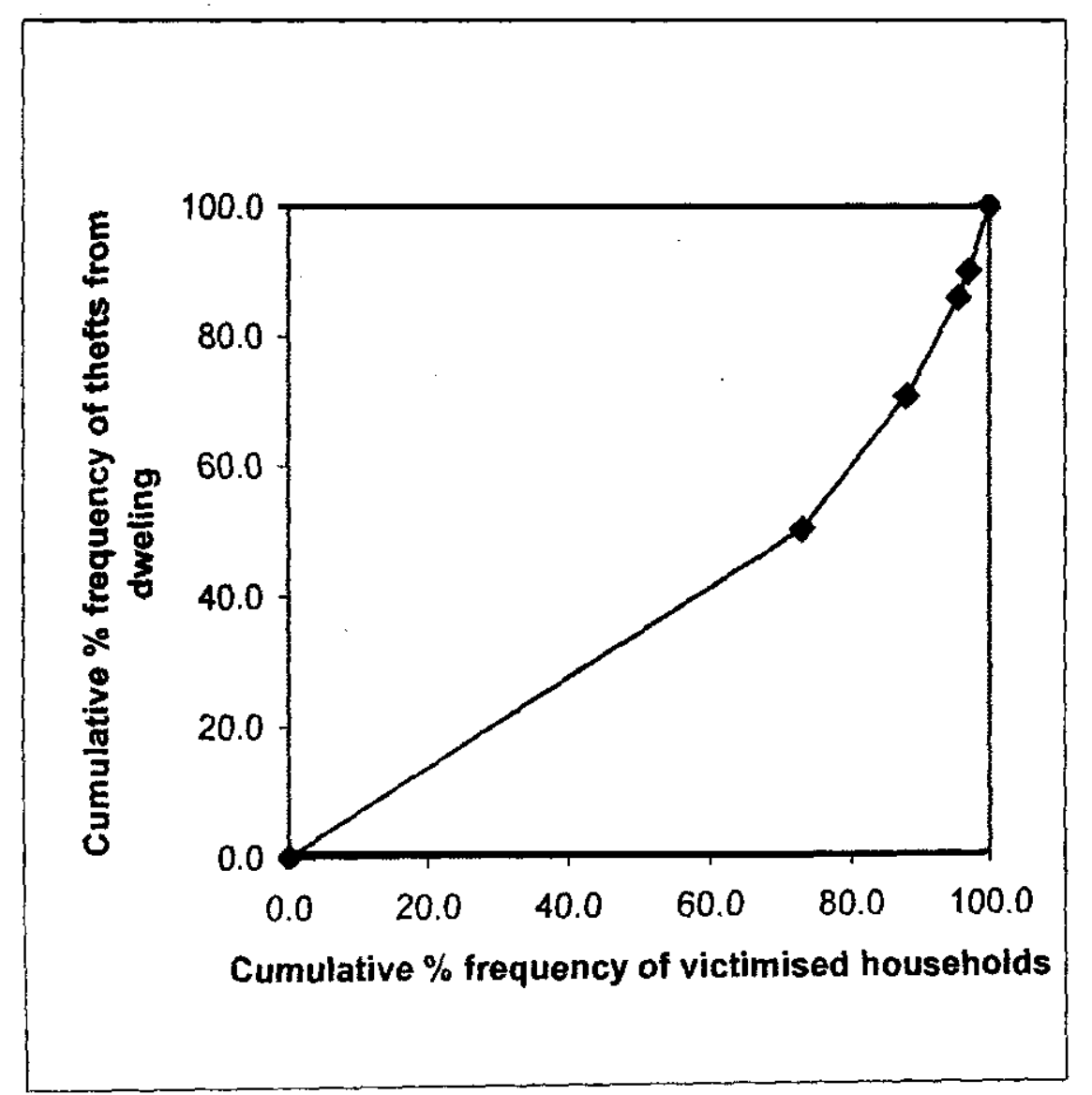

Figure 7. Lorenz curve for thefts from dwelling over victims.

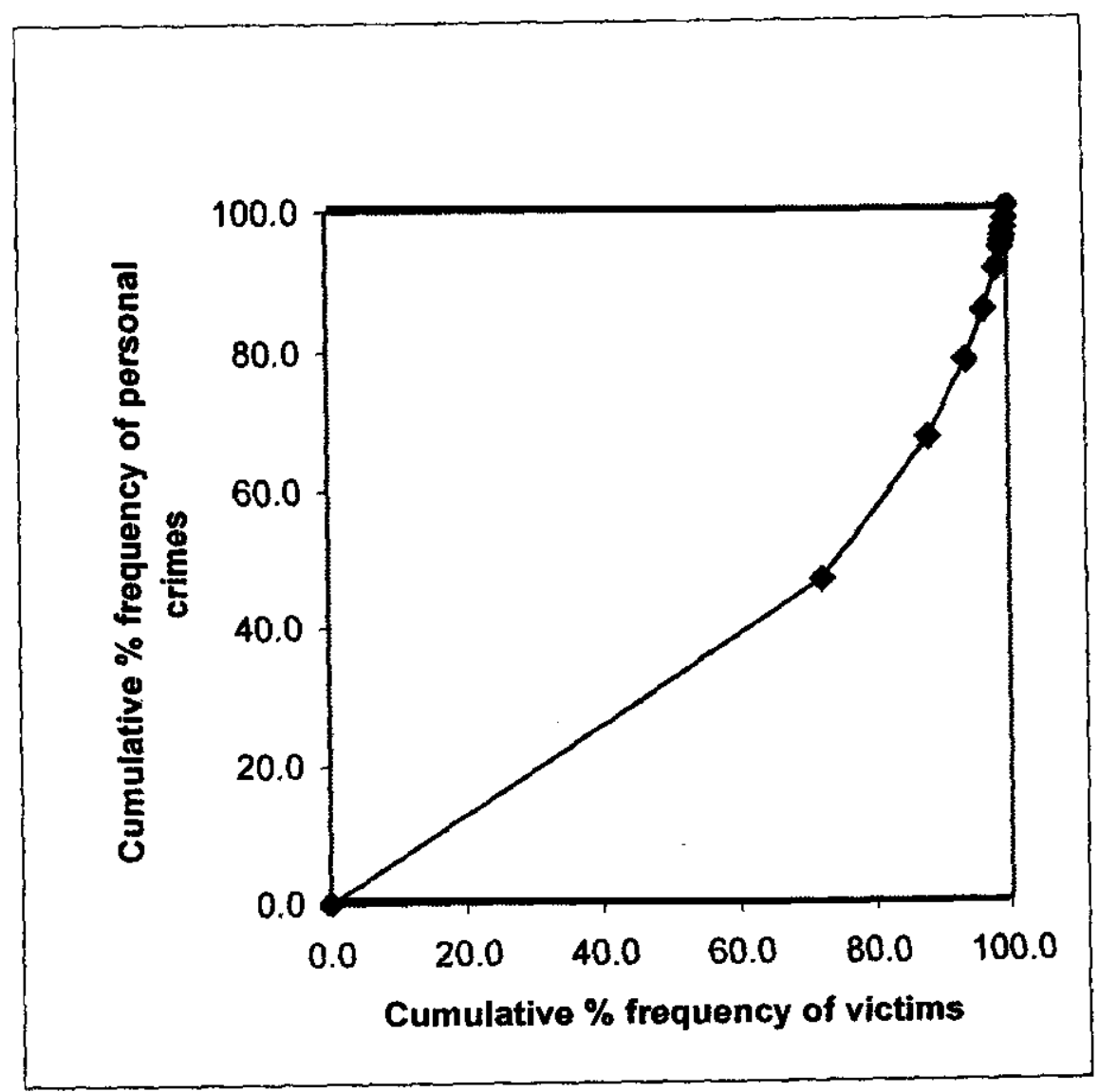

Figlere \& I nrenz nurve fror total narennal nrimas nuar vintima 


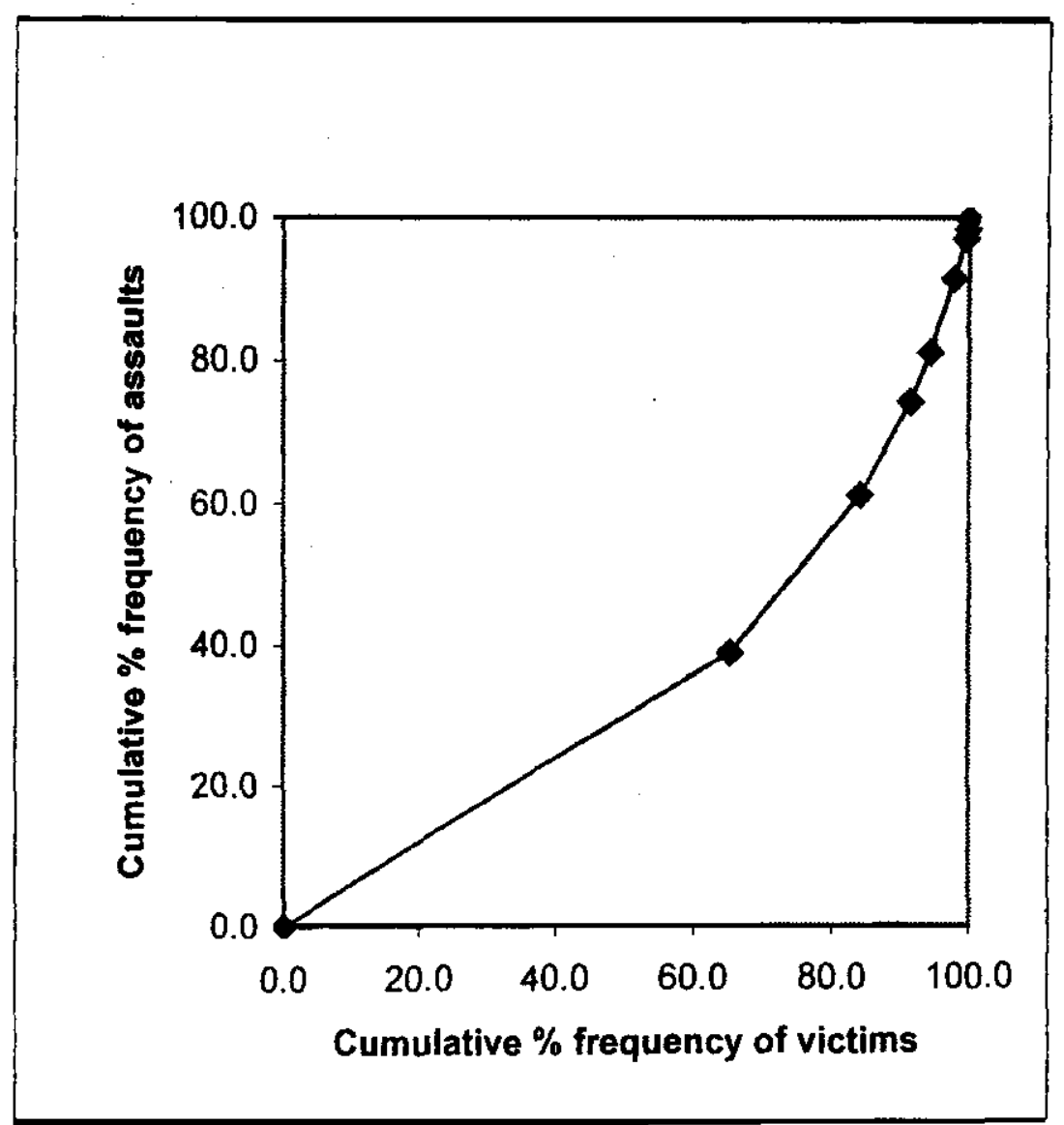

Figure 9. Lorenz curve for total assaults over victims.

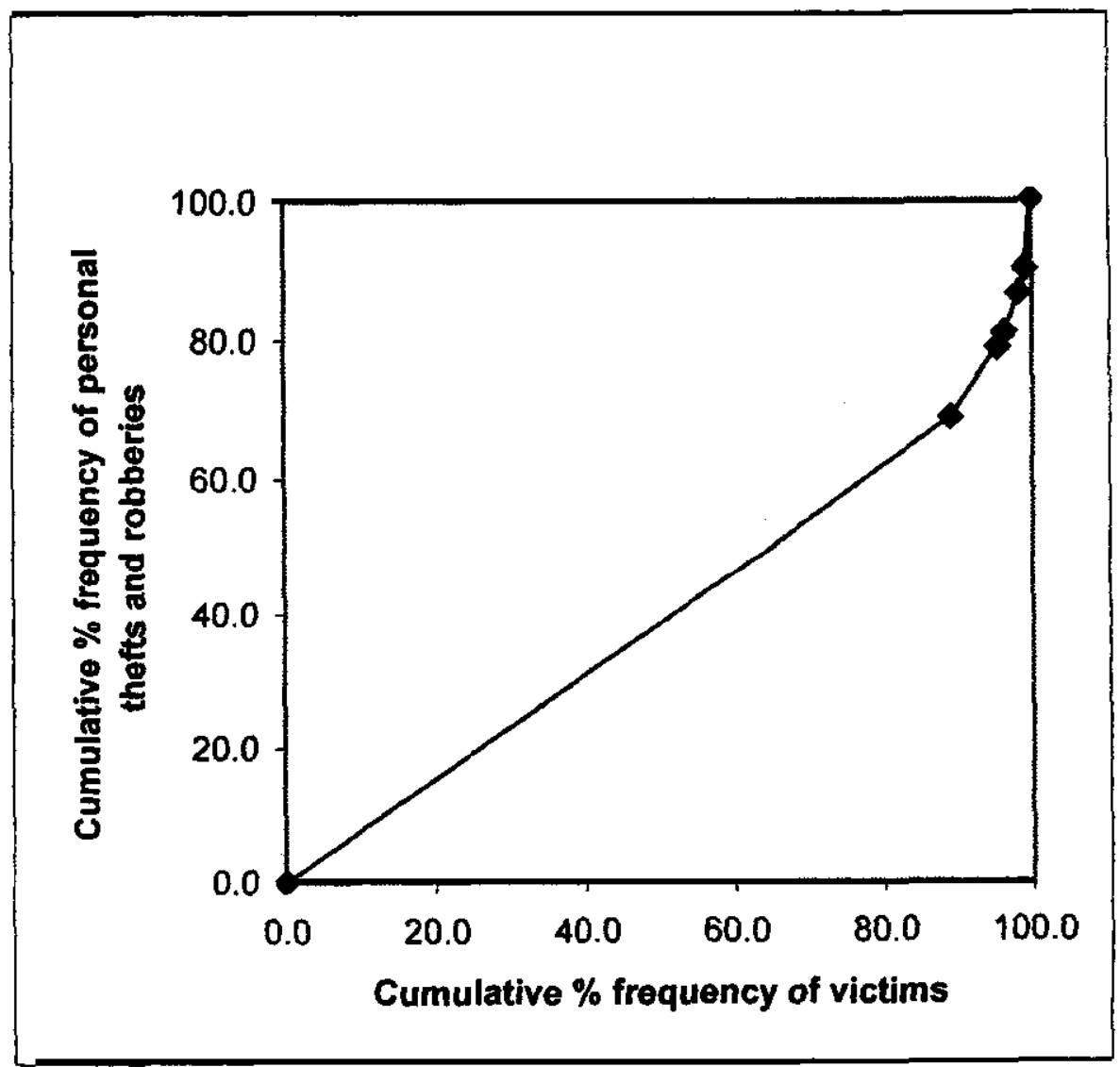

Figure 10. Lorenz curve for personal thefts and robberies over victims. 


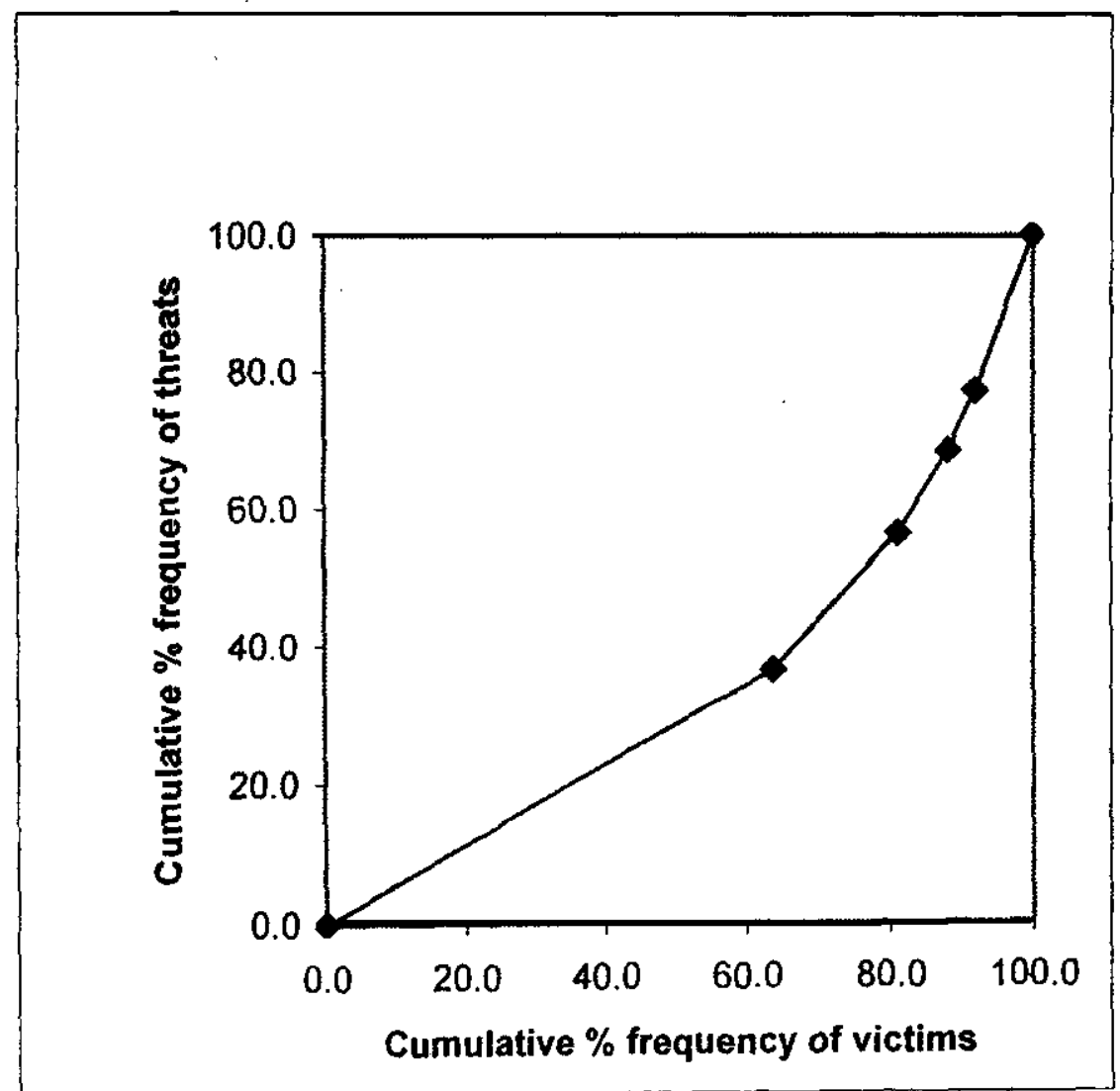

Figure 11. Lorenz curve for threats over victims.

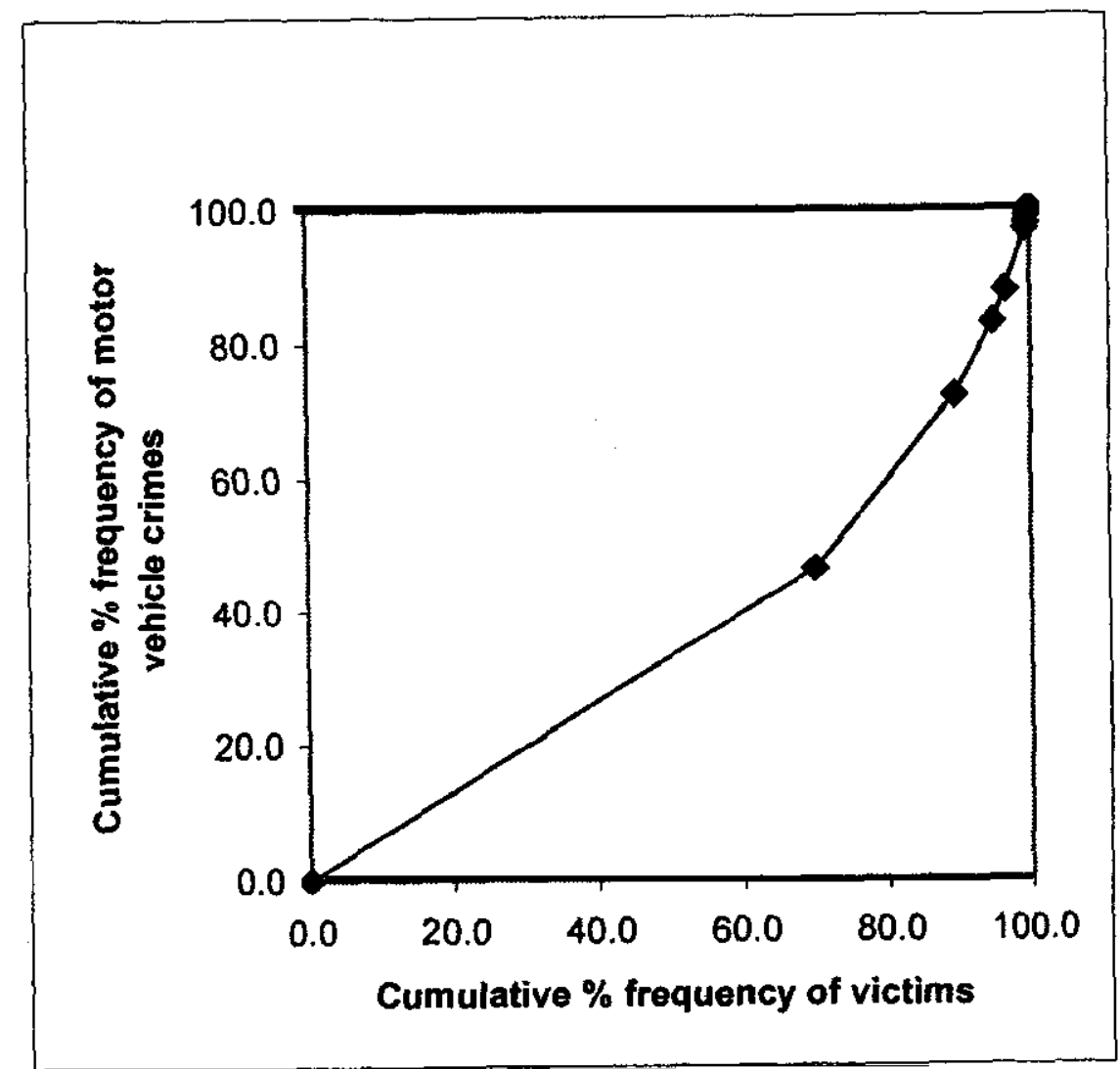

Figure 12. Lorenz curve for total motor vehicle crimes over victims. 


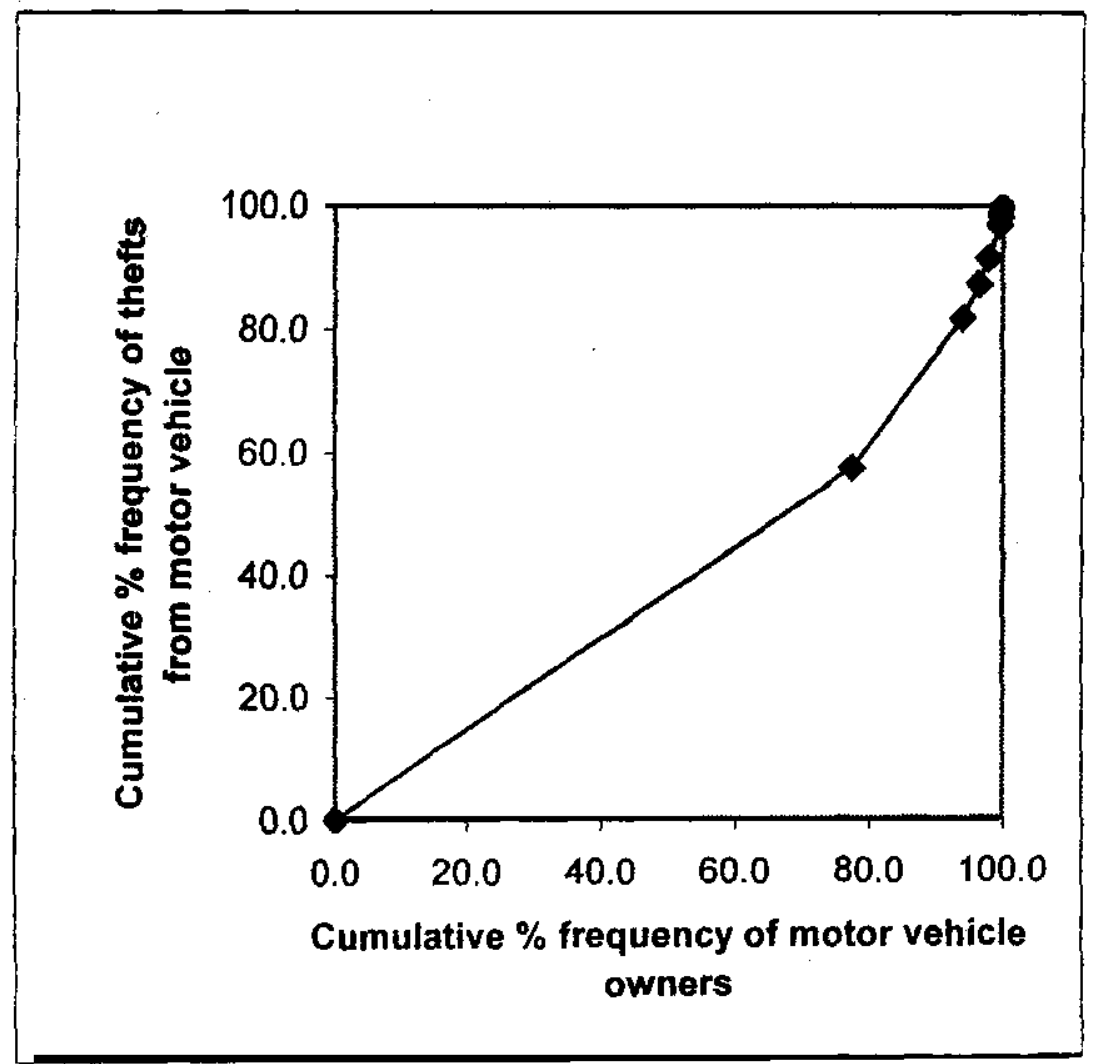

Figure 13. Lorenz curve for thefts from motor vehicle over victims.

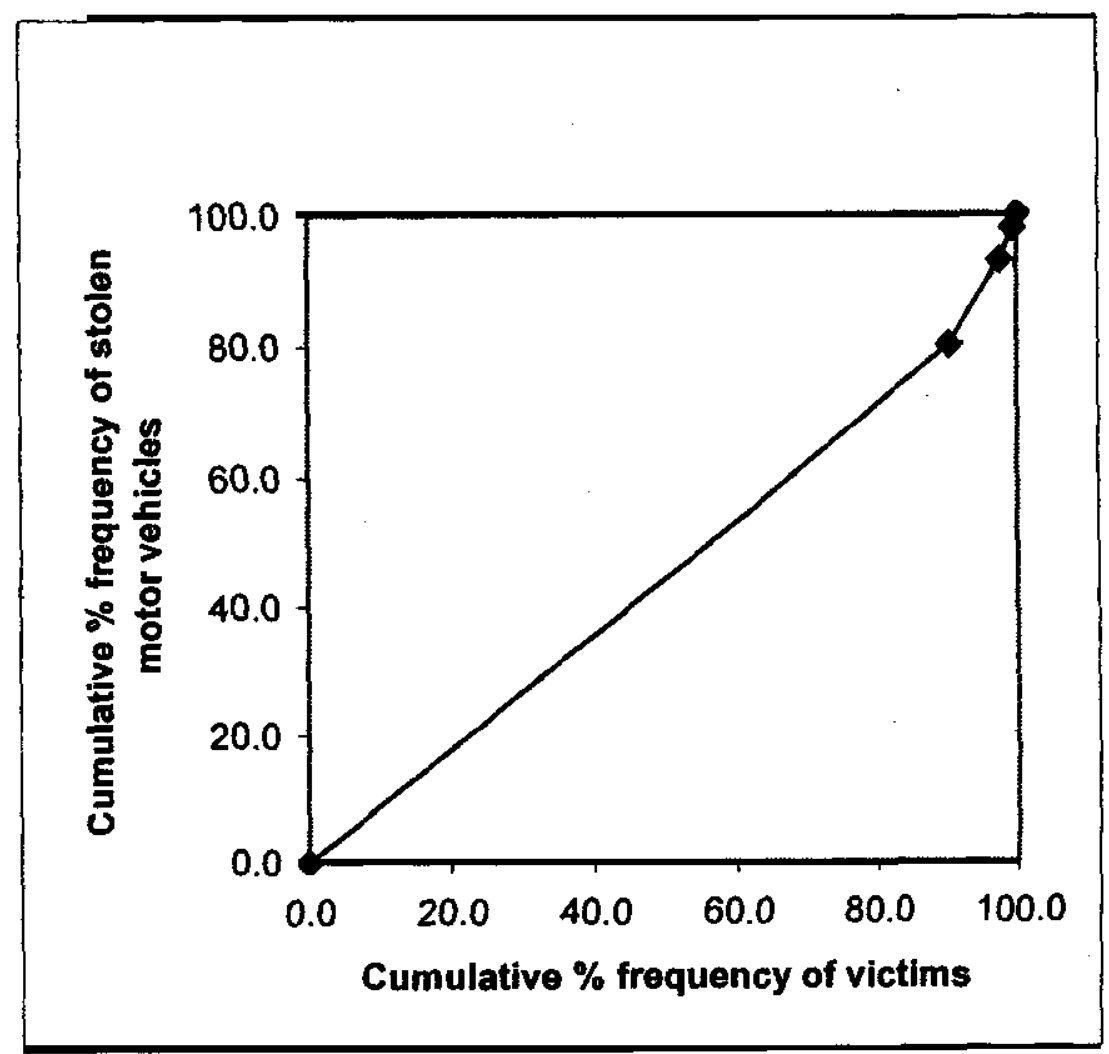

Figure 14. Lorenz curve for theft of motor vehicles over victims. 
As already mentioned, threats and to a lesser extent assaults are the crime types with most repetition (1.75 and 1.68 concentration, $63.7 \%$ and $61.2 \%$ repeat crimes and $36.4 \%$ and $34.7 \%$ repeat victims, respectively). By contrast, thefts of motor vehicles are least repeated during a calendar year (1.13 concentration, $19.1 \%$ repeats and $9.7 \%$ repeat victims). The Lorenz curve for victims of theft of vehicles essentially coincides with the main diagonal in Figure 20. That said, the fact that some one in ten of those suffering a vehicle theft will suffer another within a year (most very much sooner, see for example Pease, 1998) provides a level of victimization much above prevalence, so even in these cases the targeting of prevention effort on prior victims is not a pointless exercise.

\section{WHO IS THE REPEAT VICTIM?}

Hindelang and colleagues in their pivotal work (Hindelang et al., 1978) and since then many others (e.g. Laub, 1997), as well as regular crime survey reports (e.g. Kershaw et al., 2000) delineate victims or describe the patterns of victimization via contingency table analysis of victim / not a victim against various demographic and socio-economic characteristics as well as lifestyle patterns. Empirical logit regression analysis of victim / not a victim is commonly employed to ascertain which individual attributes (sometimes with the addition of community characteristics) influence the probability of being victimized (to name but a few: Maxfield, 1987; Kennedy and Forde, 1990; Trickett et al., 1995).

In a sense the 'profile' of the repeat victim might be similarly drawn. Osborn and colleagues, however, concluded that '.. the set of explanatory variables at [their] disposal ... [did] not convincingly indicate which victims [would] be revictimized. In that sense, multiple victims are not different from single victims' (Osborn et al., 1996: p. 241). Repeat victims simply have more of the attributes which are associated with victimization and these characteristics remain after the initial occurrence. In addition, 'probabilities of repeat victimization will tend to be more similar across households than initial victimization risks' (Osborn et al., 1996: p. 241). 'Even initial low-risk ... households have a very substantial risk of becoming multiple victims' (Osborn et al., 1996: p. 242). Additional research evidenced that repeat victimization is best examined together with single and no victimization via models of crime counts, which occur within a period, rather than as a qualitatively different category of victim status (Tseloni et al., 2002). This empirical evidence, therefore, is against drawing 'the repeat victim profile' via contingency table analysis or 'repeat victim versus single victim' logit regression analysis. 


\section{POSSIBLE CAVEATS - CONCLUDING REMARKS}

The crime Lorenz curves presented here draw on survey data and consequently may be subject to all the statistical problems generally associated with surveys, such as sampling error and non-response bias, and particularly crime surveys, namely measurement error or under-representation of some highly victimized groups (Hough, 1987), response bias and telescoping (Schneider, 1981; Skogan, 1981). The last refers to false identification within the reference period of incidents, which occurs outside the survey period of study, or failure to recall and/or report incidents, which occurs within the survey's reference period. Measurement error and telescoping may seriously affect repeat victimization rates. In practice, crime surveys employ sampling and questionnaire techniques which minimize possible errors and biases. Weights, which correct any underrepresentation of population subgroups, are also applied (Kershaw et al., 2000).

Crime Lorenz curves may be drawn from police data as readily as from victimization surveys. These may entail different problems from crime surveys, such as differential non-reporting of crimes, reluctance of some victims to contact the police, inadequate recording of victim information, or simple spelling mistakes which impede the identification of repeats in police records (Gottfredson and Hirshi, 1987; Maguire, 1997; Matthews et al., 2001). Therefore some care should be taken to cross-check any raw crime data before drawing crime Lorenz curves.

The BCS allows for a maximum of five similar crime events in a series, as mentioned in the preamble to this paper. Were this truncation removed, crime inequality would increase since the same number of victims would seem to have experienced more crimes. For instance, property and personal crime incidence would rise from 2.9 and 2.3 to 5.8 and 3.4, respectively, if the actual number of incidents reported by victims of series entered calculations of crime rates in the $2000 \mathrm{BCS}$. This raises a number of issues, such as how much chronic victimization ought to be allowed to affect national rates and whether series victimization can conform with the common view of crimes as separate events rather than continuous processes, which clearly fall outside the scope of this paper. Insofar as respondents are believed, the human consequence is that a minority of people suffer criminal predation very frequently, with consequent effects upon their overall quality of life.

The crime Lorenz curve is a methodological instrument of some utility. Applying this statistic does not imply, certainly not at the national level, that the curve ought to be positioned nearest the equality diagonal. In this sense national crime Lorenz curves are not analogous to egalitarian perceptions of income distributions ${ }^{3}$. By contrast the ideal national crime distribution from a welfare point of view would indeed represent equality, achieved by being flat at 0 crimes with an incomplete Lorenz curve coinciding with the horizontal axis. Crime prevention strategies in principle move national crime Lorenz curves towards the perfect inequality point to minimize prevalence rates. Arguably crime prevention 
ought also to decrease repeat victimization. Were this to be the objective of social policy, Lorenz curves over victims are perfectly analogous to their income equivalents. They would tend to move towards the equality diagonal of the Figure box as a consequence of successful crime prevention directed at the elimination of repeat victimization.

Perhaps our most grandiose aspiration for analysis of this kind is that it contextualizes crime within a framework of distributive justice, as is the case with income, morbidity and similar measures of human differences. By doing so, it directly addresses notions of fairness in the distribution of crime reductive resources which is now evident in only the crudest way. Crime has lagged behind other indices in this kind of measurement probably because for crime, an individual offender is to blame, whereas for income and morbidity, social and market forces direct attention to structures yielding inequality. Put crudely, in crime the culpability of individuals directs attention away from the redirection of resources in the cause of inequality reduction.

\section{NOTES}

1 Dr Malena Carlstedt (2001) has fitted Lorenz curves to Swedish crime data in her unpublished Master's thesis given in the References section.

2 Incidents occurred within 15 minutes walk from home. This restriction has been necessitated by subsequent analysis of area correlates on crime and lack of information on previous residence location. It significantly reduces the observed probabilities of four or less occurrences vehicle and, subsequently, total household crime (Tseloni, 2004).

3 In principle, income Lorenz curves ought to move towards the equality diagonal after state intervention (via taxation and subsidizing) has taken place. Indeed fiscal policy in most European countries reduces income inequality (Eurostat, 2002, p. 24).

\section{REFERENCES}

Carlstedt, M. (2001). Upprepad viktimisering - En studie av utsatthet ff'Ar brott i Sverige. Filosofie licentiatuppsats, Kriminologiska Institutionen, Stockholms Universitet.

Chenery, S., Ellingworth, D., Tseloni, A. and Pease, K. (1996). Crimes which Repeat: Undigested evidence from the British Crime Survey 1992. International Journal of Risk, Security and Crime Prevention, 1, 207-216.

Eurostat (2002). The Social Situation in the European Union 2002. http://europa.eu.int/comm/eurostat/datashop.

Farrell, G. (1992). Multiple victimisation: its Extent and Significance. International Review of Victimology, 2, 85-102.

Farrell, G. (1995). Predicting and Preventing Revictimisation. In Building a Safer Society (M. Tonry and D.P. Farrington, eds). Crime and Justice 19. University of Chicago Press; Chicago.

Farrell, G. and Pease, K. (Eds.) (2001). Repeat Victimisation. Criminal Justice Press; Monsey, NY. Forrester, D., Frenz, S., O'Connor, M. and Pease, K. (1990). The Kirkholt Burglary Prevention Project. Phase II. Crime Prevention Unit Paper 23. Home Office; London. 
Garland, D. (1997). Of Crimes and Criminals: The development of Criminology in Britain. In The Oxford Handbook of Criminology (M. Maguire, R. Morgan and R. Reiner, eds). Clarendon Press; Oxford.

Gottfredson, M.R. and Hirshi, T. (1987). Positive Criminology. Sage; Thousand Oaks.

Hales, J., Henderson, L., Collins, D. and Becher, H. (2000). 2000 British Crime Survey (England and Wales): Technical Report. National Centre for Social Research; London.

Hindelang, M., Gottfredson, M.R. and Garrafalo, J. (1978). Victims of Personal Crime: an Empirical Foundation for a Theory of Personal Victimisation. Ballinger; Cambridge, MA.

Hough, M. (1987). Crime Surveys and Crime Risks. Paper presented at the Workshop on the Design and Use of the National Crime Survey, Maryland, July 1987.

Karmen, A. (2001). Crime Victims: An Introduction to Victimology. 4th edition. The Wadsworth Contemporary Issues in Crime and Justice Series. Wadsworth/Thomson Learning; Belmont CA.

Kennedy, L.W. and Forde, D.R. (1990). Routine Activities and Crime: An Analysis of Victimisation in Canada. Criminology, 28, 137-152.

Kershaw, C., Budd, T., Kinshott, G., Mattison, J., Mayhew, P. and Myhill, A. (2000). The 2000 British Crime Survey, England and Wales. Home Office Statistical Bulletin 18/2000. Home Office; London.

Laub, J. (1997). Patterns of Criminal Victimization in the United States. In Victims of Crime (L. Davis and W. Skogan, eds). 2nd edition. Sage; Thousand Oaks.

Maguire, M. (1997). Crime Statistics, Patterns and Trends: Changing Perceptions and their Implications. In The Oxford Handbook of Criminology (M. Maguire, R. Morgan and R. Reiner, eds). Clarendon Press; Oxford.

Marsh, C. (1988). Exploring Data: An Introduction to Data Analysis for Social Scientists. Polity Press; Cambridge.

Marshall, A. (1890). Principles of Economics.

Matthews, R., Pease, C. and Pease, K. (2001). Repeat victimisation of Banks, Building Societies, Betting Shops and Jewellers: Themes and Variations. In Repeat Victimisation (G. Farrell, and K. Pease, eds). Harrow and Heston; Guildesland, NY.

Maxfield, M. (1987). Household Composition, Routine Activity, and Victimization: A Comparative Analysis. Joumal of Quantitative Criminology, 3, 301-320.

Osborn, D.R., Ellingworth, D., Hope, T. and Trickett, A. (1996). Are Repeatedly Victimised Households Different? Joumal of Quantitative Criminology, 12, 223-245.

Pease, K. (1998). Repeat Victimisation: Taking Stock. Crime Detection and Prevention Series Paper No. 90. Home Office; London.

Reiss, A. (1980). Victim proneness in repeat victimization by type of crime. In Indicators of Crime and Criminal Justice: Quantitative Studies (S. Fienberg, and A. Reiss, eds). Bureau of Justice Statistics; Washington, DC

Schneider, A.L. (1981). Methodological Problems in Victim Surveys and their Implications for Research in Victimology. Journal of Criminal Law and Criminology, 72, 818-838.

Skogan, W.G. (1981). Issues in the Measurement of Victimisation. Bureau of Justice Statistics; U.S. Department of Justice.

Trickett, A., Osborn, D.R. and Ellingworth, D. (1995). Property Crime Victimisation: The Roles of Individual and Area Influences. International Review of Victimology, 3, 273-295.

Tseloni, A., Osborn, D.R., Trickett, A. and Pease, K. (2002). Modelling Property Crime using the British Crime Survey: What have we Learned? British Joumal of Criminology, 42, 89-108.

Tseloni, A. (2004). Multilevel Modelling of the Number of Property Crimes. Household and Area Effects. (Submitted manuscript). 